\title{
DOUBLE NEGATIVE
}

A soundless wind lifted

the dreamed jig-saw pieces

of the world, then let them fall

to lodge in the black ground of sleep:

yellow, bright blue, brown

and green, orange and pink gravestones

leaning at every angle:

contours and colors compliments

of the mad. Waking, the dreamer

is furnished every reason not to sleep.

Fearing death, he fears torture

more, but even silence has risks

by accident: the police talk

to a neighbor, a man disappears.

He tangles "no" with "not" and "not at all,"

imagines unkissable bullet hole

mouths marching across his wall.

His leaping sheep fall bloody

to a butcher. Red-eyed at dawn

he stares out the window

at the world cohering as smoke

blossoming up, like smoke

from the camps and burning cities,

to be flowers for the grave in air

of the first man who took Nothing

for an answer. He will choose now,

his "no" incommensurate against theirs,

knowing nothing fits but Nothing. 